CHI ZHANG, Ph.D.

Corresponding Author

E-mail: zhangchi@chd.edu.cn

SHIYU LIU, M.Sc.

E-mail: paozimaza@foxmail.com

Chang'an University, School of Highway

Key Laboratory for Special Area Highway Engineering of

Ministry of Education

Middle Section of Nan Erhuan Road,

Xi'an City, Shannxi Province, China

JENNIFER OGLE, Ph.D.

E-mail: ogle@clemson.edu

Clemson University

Glenn Department of Civil Engineering

S Palmetto Blvd, Clemson, SC 29634, USA

MIN ZHANG, Ph.D.

E-mail: zhangmin@chd.edu.cn

Chang'an University, School of Highway

Traffic Engineering Research Institute

Middle Section of Nan Erhuan Road,

Xi'an City, Shannxi Province, China
Traffic Engineering

Preliminary Communication

Submitted: Feb. 12, 2015

Approved: Feb. 2, 2016

\title{
MICRO-SIMULATION OF DESIRED SPEED FOR TEMPORARY WORK ZONE WITH A NEW CALIBRATION METHOD
}

\begin{abstract}
Nowadays, the studies of parameter calibration for longterm work zones are limited to driver behaviour and car-following parameters, and no research was found related to calibration of the desired speed distributions during temporary work zones. Obtaining realistic results from simulations of temporary work zones is difficult. Thus, it would be valuable for gaining more valid simulation data if a method of calibrating the desired speed distribution could be applied for traffic simulation model of highway temporary work zones. The calibration method was proposed in five steps: (1) collect and analyse data, (2) plot the travel speed cumulative frequency curves and calibrate the desired speed distribution, (3) conduct simulation runs, (4) validate the simulation results, and (5) propose a new calibration meth od, which was assessed by T-tests, and the results are very promising. Finally, a simplified calibration method called "Five-Point Method" is presented and the recommended values of five-point are given.
\end{abstract}

\section{KEY WORDS}

traffic simulation; parameter calibration; desired speed distribution; temporary work zone; Vissim;

\section{INTRODUCTION}

With the development of the transportation industry in China, more and more highways are falling into disrepair because the transportation agencies can- not keep pace with the rapid development of traffic. Inevitably, this leads to some serious early damage phenomena on highways, such as water damage, deformation, cracks, potholes and land subsidence, etc. Extending the service life of these roads would require preventive maintenance, minor repairs, and/or engineering to be carried out as soon as early signs of the damage are noted. Accomplishing this level of maintenance would create a significant increase in temporary work zones on the highway system. To avoid the inconvenience caused to normal traffic during construction on the existing roadways, the "open while working" maintenance operation is often adopted. However, work zones tend to cause hazardous conditions for vehicle drivers and maintenance workers because they generate conflicts between maintenance activities and the traffic, and therefore aggravate the existing traffic conditions. For example, most maintenance activities will reduce the number of available lanes. Affected by sudden disturbances, the drivers exhibit dangerous driving behaviours such as speed changes, dramatic changes in direction, and surprise encroachments. All of these responses will increase the accident potential. Through the analysis of the accident statistics, Schonfeld P and Chien S [1] showed that the number of highway traffic accidents in work zones accounted for $2 \% \sim 3 \%$ of those on the highways. Asad JK and 
Aemal JK [2] argued that the traffic accident rates in work zones feature sharp increase based on the analysis of traffic data. Furthermore, three studies [3, 4, $5]$ indicated that work zone crashes were more severe than other crashes.

In view of serious safety problems in work zones, a significant amount of research has been conducted. The traditional methods to study the characteristics of work zones are to manually collect data in the field using static survey instruments along a specific road and analyse the data. This method is time-consuming, labour-intensive, and sometimes dangerous - especially on roadways with high traffic volumes that make it difficult to safely perform the field measurement. In addition, data collected using this method are often too limited with respect to the research needs. Therefore, micro-simulation is increasingly a preferred method of traffic analysis for today's transportation professionals because "simulation is safer, less expensive and faster than field implementation and testing" [6]. It is a useful tool to effectively analyse and evaluate the proposed improvements and alternatives. For example, a temporary work zone can be simulated for different lane closures and its effect found before implementing it.

Vissim which is used in this study is a microscopic time step and behaviour-based simulation model. Any model created in Vissim needs to be calibrated to sufficiently represent field conditions. The default values provided by the software developers for these parameters in a simulation model are only applicable to rather specific circumstances which are often not specified in detail by the software provider. Calibration is the process in which the input parameters are refined so that the model accurately replicates the observed traffic conditions [7]. In calibration the parameters are adjusted so that the model outputs are similar to the observed data [8]. Various parameters that can be calibrated in Vissim are acceleration, desired speed, and clearance distance, emergency stopping distance, waiting time before diffusion, lane change distance, standstill distance, minimum headway and other Wiedemann parameters. Table 1 shows the research development of calibrating parameters.

In most cases, Wiedemann parameters are used to calibrate simulation models, rather than detailed driving characteristics such as the desired speed. Speed was usually considered as a critical parameter, which had great effects on road safety especially in work zones. Carried out on the detailed study of vehicle speeds at work zones, Pain concluded that the value of speed depends on the traffic volume, lane closure, traffic controls, and the location of the work zone. Richards SH and Dudek CL [31] determined the necessity of slowdowns when driving past work zones, and implemented speed limit guidelines to improve traffic safety. Virginia PS and Chard WL [32] studied the effects of speed distribution, speed limit, and lane closures on vehicle speed patterns in work zones. Migletz $J$ et al. [33] analysed the characteristics of vehicle speed and the relationship between the speed and safety level, then proposed the recommended values for speed limits and a method of implementing speed limits. In Vissim, the desired speed is an important parameter that has great effect on travelling speeds, which is defined as a distribution rather than a fixed value. Park B and Qi H [34] believed that the default desired speed distribution in Vissim may be higher than the actual distribution of the desired speed by comparing the simulation travel time and measured travel time. Zhao XF, Huang ZY and Lin HF [35] argued that the desired speed distribution is an important parameter in Vissim, and modifying the desired speed distribution would influence the difference between the simulation speed and the measured speed. Peng WX et al. [36] pointed out that the default linear distribution of desired speed in Vissim is not suitable for real traffic conditions.

In this paper, the researchers chose to calibrate the desired speed in Vissim, which is an important parameter that has a significant influence on achievable travel speeds, roadway capacity, and travel time. This article is the first to propose a new calibration method for the desired speed distribution for temporary work zones, which is referred to as the "Five-Points Method". The proposed method does not intend to replace the existing calibration methods. On the contrary, it complements the traditional calibration of micro-simulation models, such as the calibration of Wiedemann parameters. It can also provide a means to create extensive amounts of valid data that do not require field data collection. This article focuses on proposing a new method to calibrate the desired speed distribution for temporary work zones where none exist.

This article is organized as follows: the need for proposing a new method to calibrate the desired speed distribution is identified in this section. The methods for the field data collection are described in the next section. Data collection and analysis are shown in Section 3. The simulations conducted to demonstrate the feasibility of the calibration method and analysis of the results are in Section 4. A new calibration method for the desired speed distributions for temporary work zone is proposed in Section 5. Conclusions and future works are provided in the final section.

\section{OBJECT OF STUDY}

The temporary work zone chosen for this study is located on the XuChang-WeiShi Highway in Henan Province. The XuChang-WeiShi Highway has two through lanes in each direction with a design speed of $120 \mathrm{~km} / \mathrm{h}$. The section of the temporary work zone, between the beginning of Longitudinal Buffer Area and the end of Activity Area, is a single lane adjacent to the construction with a $60 \mathrm{~km} / \mathrm{h}$ speed limit. 
Table 1 - Summary of parameter calibration research literature results

\begin{tabular}{|c|c|c|}
\hline Years & Scholars & Research results \\
\hline 1991 & Benekohal RF [9] & $\begin{array}{l}\text { Established a parameter calibration process framework } \\
\text { for microscopic traffic simulation model initially. }\end{array}$ \\
\hline 1998 & Hellinga BR [10] & $\begin{array}{l}\text { Improved the parameter calibration framework based on the research of Beneko- } \\
\text { hal, which has become a widely adopted parameter calibration framework. }\end{array}$ \\
\hline 2001 & Lee DH et al. [11] & $\begin{array}{l}\text { Combined with specific parameters calibration algorithm [genetic algorithm] to } \\
\text { propose the framework of simulation model calibration. }\end{array}$ \\
\hline 2002 & Richard D et al. [12] & $\begin{array}{l}\text { Pointed out that the road network model parameters should be calibrated ac- } \\
\text { cording to the actual intersection traffic conditions, so that the model meets the } \\
\text { intersection traffic characteristics. }\end{array}$ \\
\hline 2002 & Hourdakis J et al. [13] & $\begin{array}{l}\text { Proposed a new model calibration theory to use different evaluation results mod- } \\
\text { el calibration for many times. }\end{array}$ \\
\hline 2004 & Gomes G and May A [14] & $\begin{array}{l}\text { Developed and calibrated a Vissim model for a congested freeway and investi- } \\
\text { gate the relative impacts of several driver behaviour parameters. }\end{array}$ \\
\hline 2004 & Jian S and Yang XG [15] & Used Latin square method to calibrate the parameters of the Vissim simulation. \\
\hline 2005 & Jie S [16] & $\begin{array}{l}\text { Used multiple evaluation index to quantitative calibration and combined observa- } \\
\text { tion simulation animation for qualitative calibration. }\end{array}$ \\
\hline 2006 & Yang H et al. [17] & $\begin{array}{l}\text { Calibrated driver behaviour parameters and gave reasonable value range of } \\
\text { these parameters. }\end{array}$ \\
\hline 2006 & Li ZM and Yan XY [18] & $\begin{array}{l}\text { Designed a traffic simulation model parameters calibration method based on } \\
\text { genetic algorithm, and used the calibration method for the simulation of an inter- } \\
\text { section in Shijiazhuang city. }\end{array}$ \\
\hline 2007 & Ciuffo BF et al. [19] & $\begin{array}{l}\text { Performed a sensitivity analysis first and proposed a simulation model parame- } \\
\text { ters calibration process. }\end{array}$ \\
\hline 2007 & Jian S et al. [20] & $\begin{array}{l}\text { Used genetic algorithm to calibrate the parameters of driver behaviour model for } \\
\text { East Gate area in Hefei. }\end{array}$ \\
\hline 2008 & Chitturi MV et al. [21] & $\begin{array}{l}\text { Selected default model parameters and the driver behaviour model parameters } \\
\text { for obtaining the value of capacity and queue length, and designed a simulation } \\
\text { model calibration method. }\end{array}$ \\
\hline 2008 & Lee JB and Ozbay K [22] & $\begin{array}{l}\text { Improved SPSA algorithms combined with flow and density used in the model cal- } \\
\text { ibration for highways, and used K-S test method to validate the simulation model. }\end{array}$ \\
\hline 2009 & Li YX [23] & $\begin{array}{l}\text { Used genetic algorithm and SPSA algorithm to calibrate the parameters for study- } \\
\text { ing the traffic capacity of the bus lane, and the automatic calibration program } \\
\text { was developed by using VB language and MATLAB software. }\end{array}$ \\
\hline 2010 & Yang W [24] & $\begin{array}{l}\text { Established parameters calibration method based on orthogonal test for the seg- } \\
\text { ments of urban expressway entrances and exits, and calibrated the parameters } \\
\text { of car-following models and lane-changing models. }\end{array}$ \\
\hline 2010 & Ting $\mathrm{H}[25]$ & $\begin{array}{l}\text { Proposed a method for weaving area to calibrate multi-objective planning based } \\
\text { on genetic algorithm, and developed an automatic calibration program by using } \\
\text { C\# language and MATLAB software. }\end{array}$ \\
\hline 2010 & Yu Z et al. [26] & $\begin{array}{l}\text { Proposed a parameter calibration method based on SPSA algorithm, and its re- } \\
\text { search object was the area of Beijing West Ring ZiZhu Bridge to the space bridge. }\end{array}$ \\
\hline 2011 & Zhang CC and Niu XQ [27] & $\begin{array}{l}\text { Calibrated the parameters of intersection traffic simulation model, and recom- } \\
\text { mended the values of calibrated parameters. }\end{array}$ \\
\hline 2012 & Quan Y et al. [28] & $\begin{array}{l}\text { Chose the average queue length and the traffic flow as the evaluation index, and } \\
\text { calibrated six parameters in Vissim. }\end{array}$ \\
\hline 2012 & Liu CC [29] & $\begin{array}{l}\text { Built the highway work zone simulation model in Vissim, and used the orthogonal } \\
\text { test to calibrate the parameters based on the measured data. }\end{array}$ \\
\hline 2013 & Hu XH and Yu Z [30] & $\begin{array}{l}\text { SPSA algorithm combined with genetic algorithms to form the SPGA algorithm for } \\
\text { calibrating massive transportation network simulation model in Vissim. }\end{array}$ \\
\hline
\end{tabular}

This temporary work zone was chosen first of all for its representativeness. The highway from XuChang to WeiShi, built in 2005 , is an important part of the road network in Henan Province, so premature damage has inevitably occurred on this section and the temporary work zones in this area are typical for preventive 
maintenance or minor repairs engineering. A secondary feature is the mix of vehicles and traffic conditions; the vehicles mainly include passenger cars and a moderate proportion of heavy goods vehicles and the traffic flow is typically free-flow. The design of the road in this section is also amenable to study, because the road is relatively straight and curves have extra-large radii $(5500 \mathrm{~m})$ and longitudinal grade less than $0.5 \%$, so the operation effects of the design on driving can be ignored.

\section{DATA COLLECTION AND ANALYSIS}

\subsection{Data collection}

Field data collection was performed during two days (13 14 November, 2013). In the field, researchers noted that heavy goods vehicles (HGVs) had different characteristics compared with passenger cars (Cars), which might result in different preferences for speed. Thus, two separate databases were created, one for Cars and one for HGVs and both contain vehicle speeds and traffic volume. To minimize the impacts of other factors, field data collection was conducted only during daytime from 7:00 a.m. to 6:00 p.m. For the entirety of data collection time period, the traffic flow was free flowing and the weather was clear.

For this study, vehicle speeds were measured by hand-held radar gun (error range $= \pm 2 \mathrm{~km} / \mathrm{h}$ ) at four selected sites in the temporary work zone (Figure 1). A manual count method was used to collect the traffic volume from video that was recorded in the field. This allowed the videotapes to be reviewed in the laboratory - a safer environment than the roadside.

\subsection{Data analysis}

Various statistical methods can be used to analyse vehicle speed data. These methods are chosen based on the focus of the study, and include descriptive statistics, K-S tests, and T-tests. In this paper, the K-S test showed that speed data were consistent with a normal distribution (Table 2), and T-tests were performed to compare the "measured" and "simulated" speeds. And the null hypothesis $\mathrm{HO}$ of T-tests was that the measured mean speeds of Cars and HGVs were equal to the simulated mean speeds of Cars and HGVs respectively, which was applicable to all the T-tests mentioned in this paper. In addition, the Pauta Criterion method was adopted to remove the effects of abnormal data which have large statistical deviation of the numerical results. And the abnormal data will lead to simulated results far from the reality. If the measured data obey normal distribution, Pauta Criterion can be expressed as:

$$
P(|x-\mu|>3 \sigma \leq 0.003
$$

where $\mu$ is the mathematical expectation of normal distribution

$\sigma$ is the variance of normal distribution

There is tiny probability that the value of the measured data is greater than $\mu+3 \sigma$ or less than $\mu-3 \sigma$, so these measured data should be eliminated. Therefore, out of 463 measured speed observations, 457 valid samples were obtained, of which 209 valid samples were Cars and the remaining samples were HGVs. The descriptive statistics without abnormal data are shown in Table 3.

Descriptive statistics showed that $74.9 \%$ of Cars were driven at speeds of $70 \mathrm{~km} / \mathrm{h} \sim 110 \mathrm{~km} / \mathrm{h}$, while

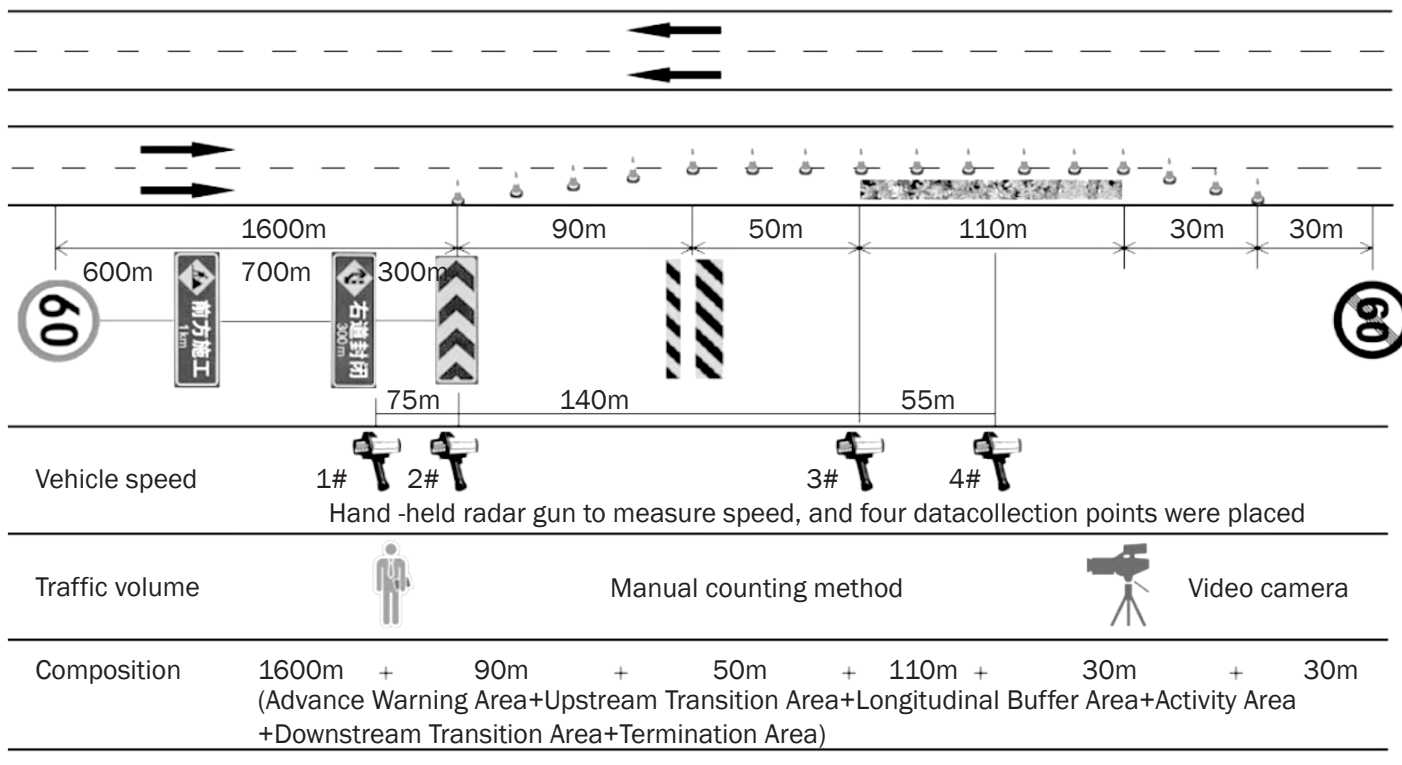

Figure 1 - The schematic diagram of the temporary work zone 
Table 2 - Results of Kolmogorov-Smirnov Test

\begin{tabular}{|c|c|c|c|}
\hline \multicolumn{2}{|c|}{ Statistical items } & Measured speed of Cars & Measured speed of HGVs \\
\hline \multicolumn{2}{|c|}{ Sample size } & 209 & 248 \\
\hline \multirow{2}{*}{ Normal parameters ${ }^{\mathrm{a}, \mathrm{b}}$} & Mean & 93.9 & 71 \\
\hline & Std.Deviation & 17.824 & 8.608 \\
\hline \multirow{3}{*}{ Most extreme differences } & Absolute & 0.071 & 0.063 \\
\hline & Positive & 0.069 & 0.063 \\
\hline & Negative & -0.071 & -0.057 \\
\hline \multicolumn{2}{|c|}{ Kolmogorov-Smirnov Z } & 1.037 & 0.998 \\
\hline \multicolumn{2}{|c|}{ Asymp. Sig. (2-tailed) } & 0.232 & 0.272 \\
\hline
\end{tabular}

Note: a. Test distribution is Normal.

b: Calculated from data.

Table 3 - Descriptive statistics without abnormal data

\begin{tabular}{|c|c|c|c|c|c|c|c||}
\hline \hline Vehicle Types & Sample size & Mean & Minimum & Maximum & Median & Mode & $\begin{array}{c}\text { Standard } \\
\text { deviation }\end{array}$ \\
\hline \hline Cars & 209 & 93.9 & 43 & 141 & 97 & 101 & 17.824 \\
\hline HGVs & 248 & 71.0 & 45 & 107 & 71 & 72 & 8.608 \\
\hline
\end{tabular}

$63.5 \%$ of HGVs were driven at speeds of $65 \mathrm{~km} / \mathrm{h} \sim 80$ $\mathrm{km} / \mathrm{h}$ during active temporary work zones. The compliance rate with the construction speed limit was $2.37 \%$ for Cars and $9.52 \%$ for HGVs. The average speed of Cars was $93.9 \mathrm{~km} / \mathrm{h}$, which was $33.9 \mathrm{~km} / \mathrm{h}$ higher than the speed limit of $60 \mathrm{~km} / \mathrm{h}$. Similarly, the average speed of HGVs was $71.0 \mathrm{~km} / \mathrm{h}, 21 \mathrm{~km} / \mathrm{h}$ higher than the speed limit. Both the average speeds of Cars and HGVs were lower during construction than 106.2 $\mathrm{km} / \mathrm{h}$ and $78.6 \mathrm{~km} / \mathrm{h}$, respectively, which were measured when the temporary work zone was not in effect. The lack of other speed controlling factors on the sight enabled a good representation of the desired speeds in the work zone. At this location, the only method of speed control was a speed limit sign indicating 60 $\mathrm{km} / \mathrm{h}$. Therefore, speeds measured both with and without the temporary work zone in place were higher than the speed limit. However, the average speed in the work zone was significantly less than without work zone indicating that the work zone interfered with the normal traffic flow. Given the lack of existing calibration research on the speed distributions for temporary work zones, the researchers used these data to propose a new method to calibrate the desired speed distribution for temporary work zones in Vissim.

\subsubsection{The travelling speed cumulative frequency curve}

The travelling speed cumulative frequency curve was found to be a good fit for the desired speed distribution. Based on the statistics of valid field data, the travelling speed cumulative frequency curves of Cars and HGVs were plotted in Figure 2, respectively.

As Figure 2a shows, the curve for Cars became gradually steeper at eight percentile and flattened out around 83 percentile. Figure $2 b$ shows that the curve for HGVs became gradually steeper from the 20 percentile and flatter after 84 percentile. Taking into account the different types of vehicles, the 15th percentile (V15) and 85th percentile (V85) values of the travel speed cumulative frequency curve can be considered as two critical control points. The shape of curves was also similar to the typical "S" curve. Curves were relatively flat below $\mathrm{V} 15$ and above V85, while relatively steep between $\mathrm{V} 15$ and $\mathrm{V} 85$. In addition, the V15 of Cars and HGVs was $71.0 \mathrm{~km} / \mathrm{h}$ and $60.5 \mathrm{~km} / \mathrm{h}$, respectively, while the corresponding V85 was 106.2 $\mathrm{km} / \mathrm{h}$ and $77.0 \mathrm{~km} / \mathrm{h}$, respectively.

\subsubsection{The desired speed distribution}

The desired speed distribution was composed of the speed intervals and the cumulative frequency of each interval. In this study, the travelling speed cumulative frequency curves were considered to be the desired speed distribution. As noted previously, V15 and V85 were of great importance for the travelling speed cumulative frequency curve, so V15 and V85 can be defined as the minimum and maximum of the desired speed distribution. In order to make the simulation results as realistic as possible, other control points were determined by equisection method (Table 4). The travel speeds taken from Figure 2 were assumed to be the desired speeds correspondingly (Table 4).

\section{SIMULATION AND ANALYSIS}

\subsection{Simulation environment}

According to the field conditions, the road networks were created in Vissim. The highway had two lanes in each direction with one lane under an active work 


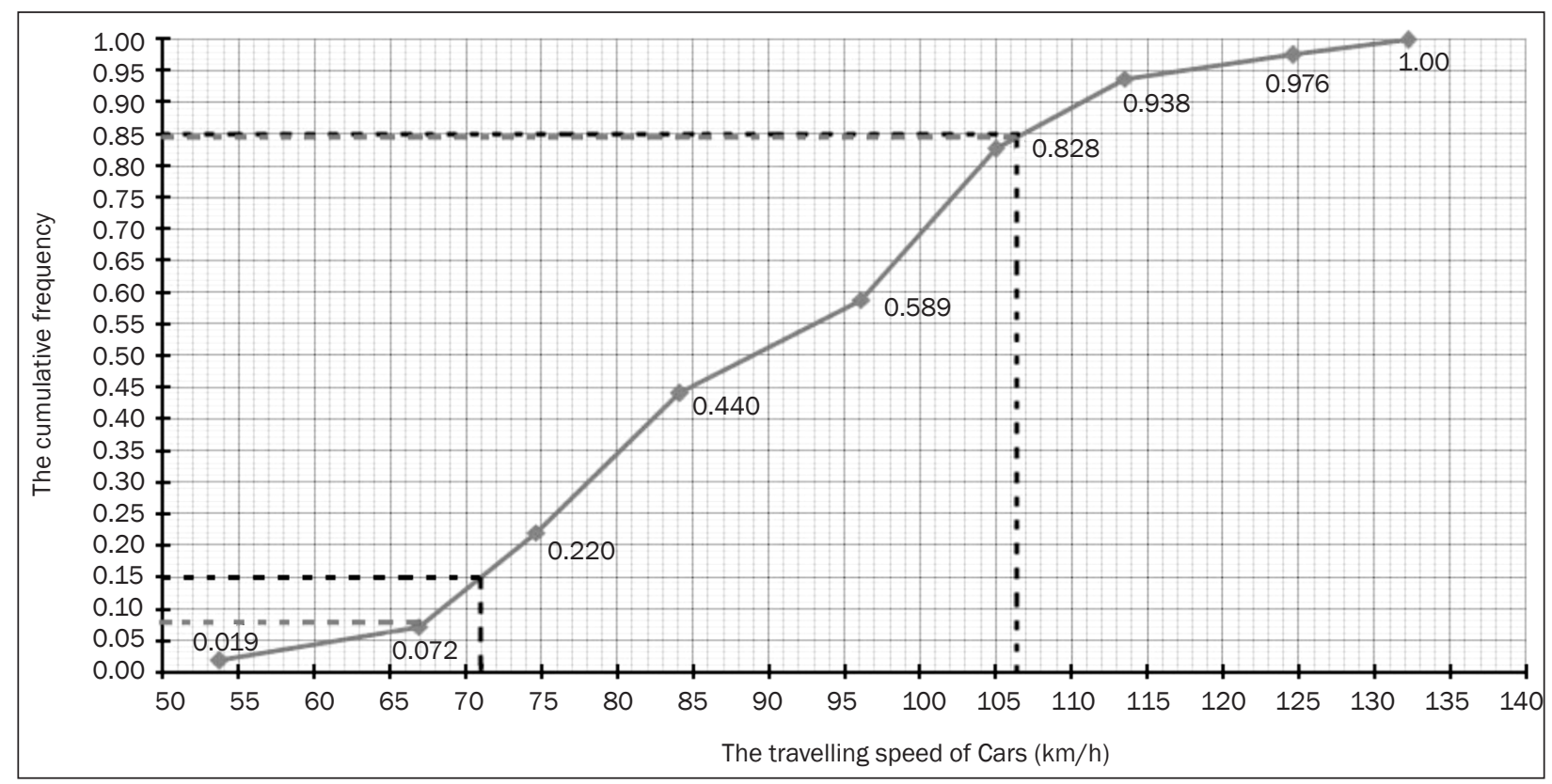

Figure $2 a$ - The travelling speed cumulative frequency curves for Cars

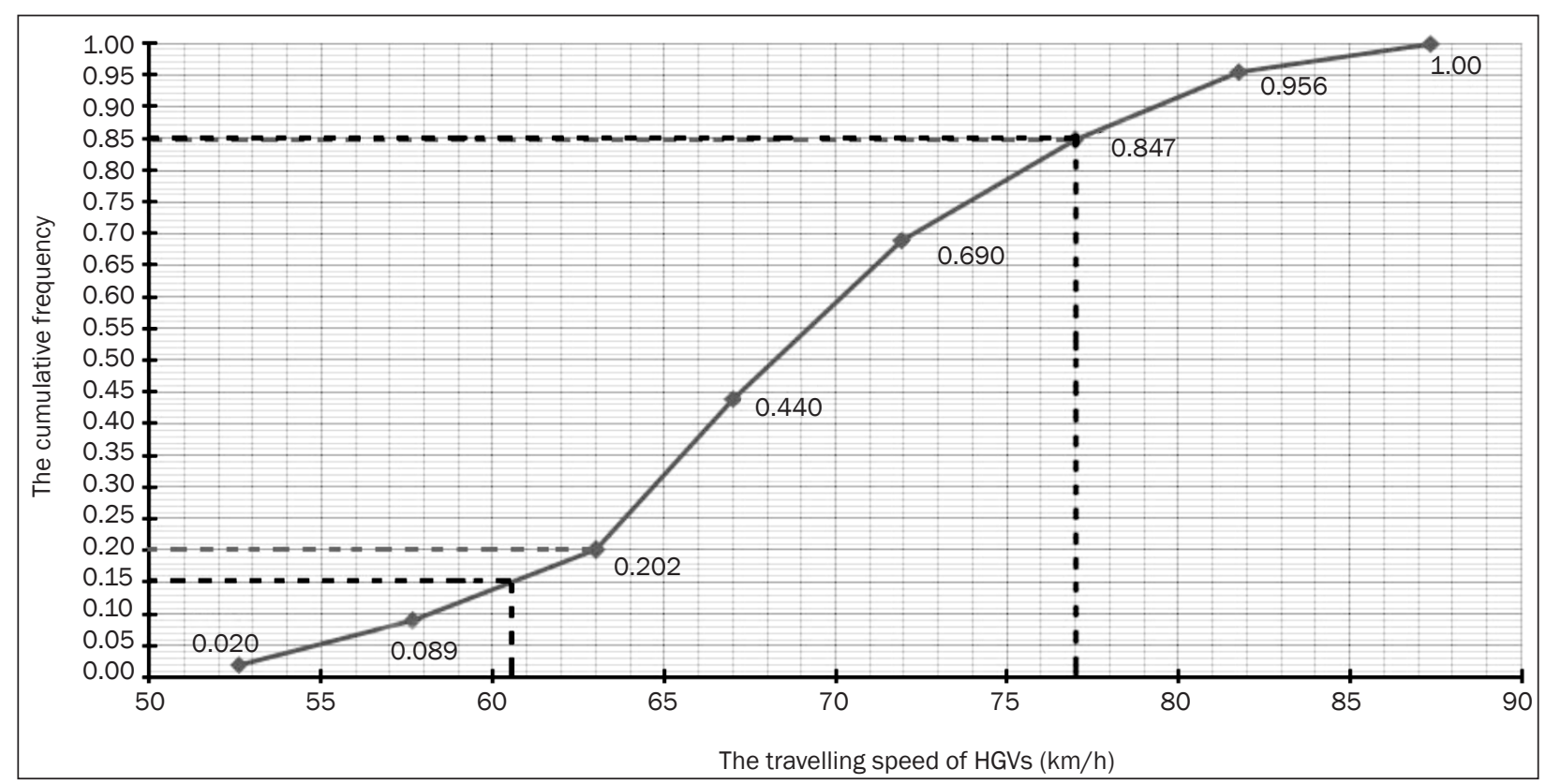

Figure $2 b$ - The travelling speed cumulative frequency curves for HGVs

Table 4 - The desired speeds

\begin{tabular}{||c|c|c|c|c|c|c|c|c|c|c|c||}
\hline $\begin{array}{c}\text { Desired speed } \\
\text { cumulative frequency }\end{array}$ & $0 \%$ & $10 \%$ & $20 \%$ & $30 \%$ & $40 \%$ & $50 \%$ & $60 \%$ & $70 \%$ & $80 \%$ & $90 \%$ & $100 \%$ \\
\hline $\begin{array}{c}\text { Desired speeds } \\
\text { of Cars (km/h) }\end{array}$ & 71.0 & 74.8 & 77.3 & 81.0 & 83.3 & 89.0 & 94.8 & 97.0 & 100.2 & 103.1 & 106.2 \\
\hline $\begin{array}{c}\text { The desired speeds } \\
\text { of HGVs (km/h) }\end{array}$ & 60.5 & 63.2 & 64.5 & 65.5 & 66.7 & 68.2 & 69.5 & 71.0 & 72.4 & 74.8 & 77.0 \\
\hline
\end{tabular}

zone. The lanes were 3.5 meters wide each. Other parameters required data from the field to maintain consistency with actual traffic conditions including traffic volume, vehicle type, traffic composition and the desired speed distributions which were initially calibrated in Figure 3. The researchers found that the 
implementation of this work zone and the resulting lane reduction lead to the formation of conflict areas. With proper settings for driving rules, the traffic operations would remain smooth. In the final model, four data collection points were set at the same locations as the field, and the output was equal to the field measured mean speed.

\subsection{Initial calibration of desired speed distribution}

Based on the data in Table 2, the desired speed distributions were calibrated by setting the critical control points for the curves (Figure 3).

\subsection{Simulation results and analysis}

Four groups of data collected from the field were used in the simulation. What needs to be explained is that an equivalent hourly traffic volume in passenger cars was calculated for the site using the HGV adjustment factors of 1.5, and the conversion has been done shown in Table 5. As Table 5 shows, the simulated speeds were significantly lower than the measured speeds in all groups, and the mean relative errors for Cars and HGVs were $16.49 \%$ and $8.88 \%$, respectively. T-tests showed that p-values of Cars and HGVs were 0.000 and 0.003 , respectively, less than 0.05 . This indicated that there were significant differences between the measured mean speeds and the corresponding simulated speeds. Therefore, the initial calibrations of the desired speed distributions were not reliable, and the adjustments were revised.

\subsection{Further calibration and analysis}

To obtain more promising simulation results, factor $\mathrm{k}$ for the numerical relationship between the travel speed and the desired speed should be proposed. According to the mean ratio of the measured and simulated speeds (Table 6), the adjustment can be expressed as:

$V_{D}=k V_{T}$

where: $V_{D}$ is the desired speed; $V_{T}$ is the travelling speed; and $k$ is 1.200 for Cars and 1.098 for HGVs. The adjustment value, $k$, would be used to re-calibrate the desired speed distribution for determining new values (Table 7).

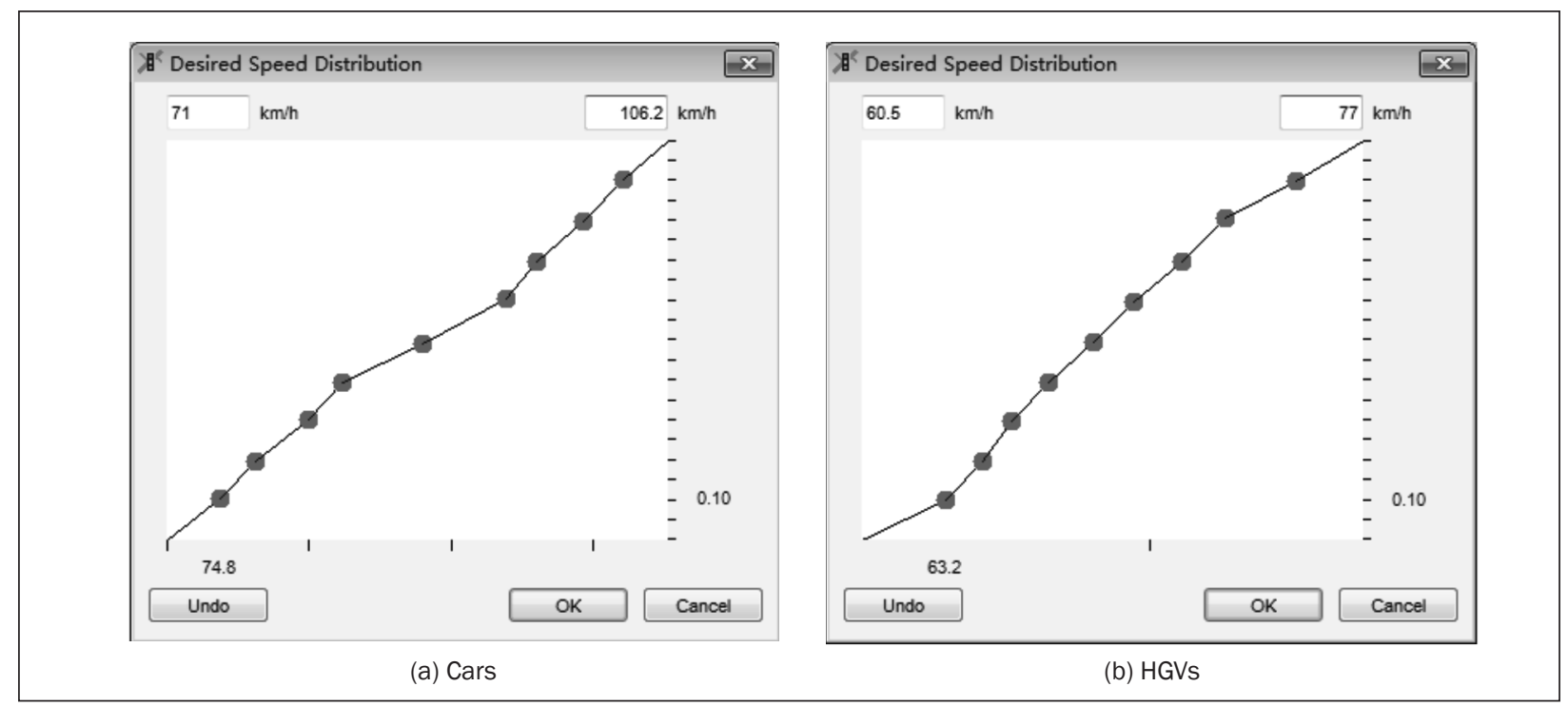

Figure 3 - The calibrated desired speed distribution

Table 5 - Summary of traffic parameters and the speeds

\begin{tabular}{|c|c|c|c|c|c|c|c|c||}
\hline \hline Groups & $\begin{array}{c}\text { Traffic } \\
\text { volume } \\
(\mathrm{pcu} / \mathrm{h})\end{array}$ & $\begin{array}{c}\text { Traffic } \\
\text { composi- } \\
\text { tion (Cars: } \\
\text { HGVs) }\end{array}$ & $\begin{array}{c}\text { Measured } \\
\text { mean } \\
\text { speed } \\
\text { of Cars } \\
(\mathrm{km} / \mathrm{h})\end{array}$ & $\begin{array}{c}\text { Simulated } \\
\text { speed } \\
\text { of Cars } \\
(\mathrm{km} / \mathrm{h})\end{array}$ & $\begin{array}{c}\text { Relative } \\
\text { error for } \\
\text { Cars }\end{array}$ & $\begin{array}{c}\text { Measured } \\
\text { mean } \\
\text { speed } \\
\text { of HGV } \\
(\mathrm{km} / \mathrm{h})\end{array}$ & $\begin{array}{c}\text { Simulated } \\
\text { speed } \\
\text { of HGV } \\
(\mathrm{km} / \mathrm{h})\end{array}$ & $\begin{array}{c}\text { Relative } \\
\text { error for } \\
\text { HGVs }\end{array}$ \\
\hline \hline 1 & 441 & $91: 207$ & 93.8 & 80.1 & $14.61 \%$ & 71.2 & 64.5 & $9.41 \%$ \\
\hline 2 & 558 & $62: 136$ & 100.4 & 78.0 & $22.31 \%$ & 72.5 & 64.5 & $11.03 \%$ \\
\hline 3 & 392 & $91: 177$ & 94.3 & 79.5 & $15.69 \%$ & 69.5 & 64.4 & $7.34 \%$ \\
\hline 4 & 435 & $77: 276$ & 91.5 & 79.3 & $13.33 \%$ & 69.9 & 64.5 & $7.73 \%$ \\
\hline
\end{tabular}


Table 6 - Analysis of the measured and simulated speeds

\begin{tabular}{||c|c|c|c|c|c||}
\hline \multirow{3}{*}{ Vehicle Types } & Groups & $\begin{array}{c}\text { Measured mean } \\
\text { speed }(\mathrm{km} / \mathrm{h})\end{array}$ & $\begin{array}{c}\text { Simulated speed } \\
(\mathrm{km} / \mathrm{h})\end{array}$ & $\begin{array}{c}\text { Differences of the } \\
\text { measured and } \\
\text { simulated speed } \\
(\mathrm{km} / \mathrm{h})\end{array}$ & $\begin{array}{c}\text { Ratio of the } \\
\text { measured and } \\
\text { simulated speed }\end{array}$ \\
\hline \hline \multirow{5}{*}{ Cars } & 1 & 93.8 & 80.1 & 13.7 & 1.171 \\
\cline { 2 - 6 } & 2 & 100.4 & 78.0 & 22.4 & 1.287 \\
\cline { 2 - 6 } & 3 & 94.3 & 79.5 & 14.8 & 1.186 \\
\cline { 2 - 6 } & 4 & 91.5 & 79.3 & 12.2 & 1.154 \\
\hline \multirow{3}{*}{ HGVs } & 1 & 71.2 & 64.5 & 6.7 & 1.200 \\
\cline { 2 - 6 } & 2 & 72.5 & 64.5 & 8.0 & 1.124 \\
\cline { 2 - 6 } & 3 & 69.5 & 64.4 & 5.1 & 1.079 \\
\cline { 2 - 6 } & 4 & 69.9 & 64.5 & 5.4 & 1.084 \\
\hline
\end{tabular}

Table 7 - New desired speeds with factor $k$

\begin{tabular}{|c|c|c|c|c|c|c|c|c|c|c|c|}
\hline $\begin{array}{c}\text { Desired speed } \\
\text { cumulative frequency }\end{array}$ & $0 \%$ & $10 \%$ & $20 \%$ & $30 \%$ & $40 \%$ & $50 \%$ & $60 \%$ & $70 \%$ & $80 \%$ & $90 \%$ & $100 \%$ \\
\hline $\begin{array}{l}\text { Desired speeds } \\
\text { of Cars }(\mathrm{km} / \mathrm{h})\end{array}$ & 85.2 & 89.8 & 92.8 & 97.2 & 100.0 & 106.8 & 113.8 & 116.4 & 120.2 & 123.7 & 127.4 \\
\hline $\begin{array}{l}\text { Desired speeds } \\
\text { of HGVs (km/h) }\end{array}$ & 66.4 & 69.4 & 70.8 & 71.9 & 73.2 & 74.9 & 76.3 & 78.0 & 79.5 & 82.1 & 84.5 \\
\hline
\end{tabular}

Table 8 shows that the adjusted simulated speeds were close to the corresponding measured mean speeds. The mean relative errors for Cars and HGVs were $3.59 \%$ and $2.24 \%$, respectively.

In Table 9, the p-value of Levene's Test for Equality of Variances was 0.091, higher than 0.05, so the variances for mean speeds of Cars between the measured and the simulated were equal. And T-tests showed the p-values of Cars and HGVs were 0.125, higher than 0.05. In Table 10, the p-value of Levene's Test for Equality of Variances was 0.013 , less than 0.05 , so the variances for mean speeds of HGVs between the measured and the simulated were not equal, and T-tests showed the p-values of HGVs were 0.100 , higher than 0.05. Thus, the addition of the adjustment factor for

Table 8 - Comparison of simulated results with factor $k$

\begin{tabular}{||c|c|c|c|c|c||}
\hline \multirow{3}{*}{ Vehicle types } & Groups & $\begin{array}{c}\text { Measured mean } \\
\text { speeds }(\mathrm{km} / \mathrm{h})\end{array}$ & $\begin{array}{c}\text { Previously sim- } \\
\text { ulated speeds } \\
(\mathrm{km} / \mathrm{h})\end{array}$ & $\begin{array}{c}\text { Simulated speed } \\
\text { with factor } \mathrm{k} \\
(\mathrm{km} / \mathrm{h})\end{array}$ & $\begin{array}{c}\text { Relative error of } \\
\text { measured mean } \\
\text { speeds and new } \\
\text { simulated speeds }\end{array}$ \\
\hline \hline \multirow{3}{*}{ Cars } & 1 & 93.8 & 80.1 & 92.3 & $1.60 \%$ \\
\cline { 2 - 6 } & 2 & 100.4 & 78.0 & 91.0 & $9.36 \%$ \\
\cline { 2 - 6 } & 3 & 94.3 & 79.5 & 91.3 & $3.18 \%$ \\
\hline \multirow{3}{*}{ HGVs } & 4 & 91.5 & 79.3 & 91.7 & $0.22 \%$ \\
\cline { 2 - 6 } & 2 & 71.2 & 64.5 & 69.2 & $2.81 \%$ \\
\cline { 2 - 6 } & 3 & 69.5 & 64.5 & 69.2 & $4.55 \%$ \\
\hline
\end{tabular}

the second round of calibrations for the desired speed distributions was valid and the results of simulation were representative of the actual field conditions.

\section{A NEW CALIBRATION METHOD FOR DESIRED SPEED DISTRIBUTION}

\subsection{Five-Point Method}

Considering that the previous calibration method called Ten-Point Method is complicated and time-consuming, the "Five-Point Method" was proposed. Whether Cars or HGVs, the desired speed differences of adjacent control points were approximate within the 
cumulative frequency range of $10 \% \sim 40 \%$ and $60 \%$ $90 \%$ respectively (Table 7 ), so were the slopes. Therefore, five critical control points were reserved to propose the "Five-Point Method" (Table 11).

\subsection{Comparison and validation}

Figure 4 shows the comparison of different desired speed distributions, including the former calibrated by the Ten-Point Method $(a, b)$ and the latter calibrated by the Five-Point Method (c, d). The distributions calibrated by the Five-Point Method had approximate shapes with the previous method. A comparison among the field-measured and various simulated speeds are shown in Figure 5. The "Default (without speed limit)" represents the speeds simulated by adopting the default desired speed distributions without speed limit, the "Default (with speed limit)" represents the adoption of the default desired speed distributions with a speed limit enforced; the "Ten-Point Method" and "Five-Point Method" were the speeds simulated by adopting the desired speed distributions with different calibration methods.

Figure 5 shows the simulated speeds of "Default (without speed limit)" were much higher than the measured speeds overall except for the speed of Cars in Group 4. This difference is caused by the lack of consideration of the effects of the temporary work zone settings in the simulation. The simulated speeds of "Default [with speed limit]"were significantly lower than the measured and simulated speeds, because the compliance rate settings for speed limits in Vissim are not flexible enough to adapt to the temporary work zone, so the simulated vehicles would drive

Table 9 - Results of T-tests for Cars

\begin{tabular}{|c|c|c|c|c|c|c|c|c|c|c|}
\hline & & \multicolumn{2}{|c|}{$\begin{array}{l}\text { Levene's Test for } \\
\text { Equality of } \\
\text { Variances }\end{array}$} & \multicolumn{7}{|c|}{ T-test for Equality of Means } \\
\hline & & \multirow[t]{2}{*}{$\mathrm{F}$} & \multirow[t]{2}{*}{ Sig. } & \multirow[t]{2}{*}{$\mathrm{t}$} & \multirow[t]{2}{*}{$d f$} & \multirow[t]{2}{*}{$\begin{array}{c}\text { Sig. } \\
\text { (2-tailed) }\end{array}$} & \multirow[t]{2}{*}{$\begin{array}{l}\text { Mean } \\
\text { differ- } \\
\text { ence }\end{array}$} & \multirow{2}{*}{$\begin{array}{l}\text { Std. } \\
\text { Error dif- } \\
\text { ference }\end{array}$} & \multicolumn{2}{|c|}{$\begin{array}{l}\text { 95\% Confidence } \\
\text { interval of the dif- } \\
\text { ference }\end{array}$} \\
\hline & & & & & & & & & Lower & Upper \\
\hline \multirow{2}{*}{$\begin{array}{l}\text { The } \\
\text { mean } \\
\text { speeds } \\
\text { of Cars }\end{array}$} & $\begin{array}{c}\text { Equal } \\
\text { varianc- } \\
\text { es as- } \\
\text { sumed }\end{array}$ & 4.055 & 0.091 & 1.02 & 6 & 0.125 & 3.425 & 1.94 & -2.76 & 6.71 \\
\hline & $\begin{array}{c}\text { Equal } \\
\text { varianc- } \\
\text { es not } \\
\text { as- } \\
\text { sumed }\end{array}$ & & & 1.02 & 3.204 & 0.164 & 3.425 & 1.94 & -3.97 & 7.92 \\
\hline
\end{tabular}

Table 10 - Results of T-tests for HGVs

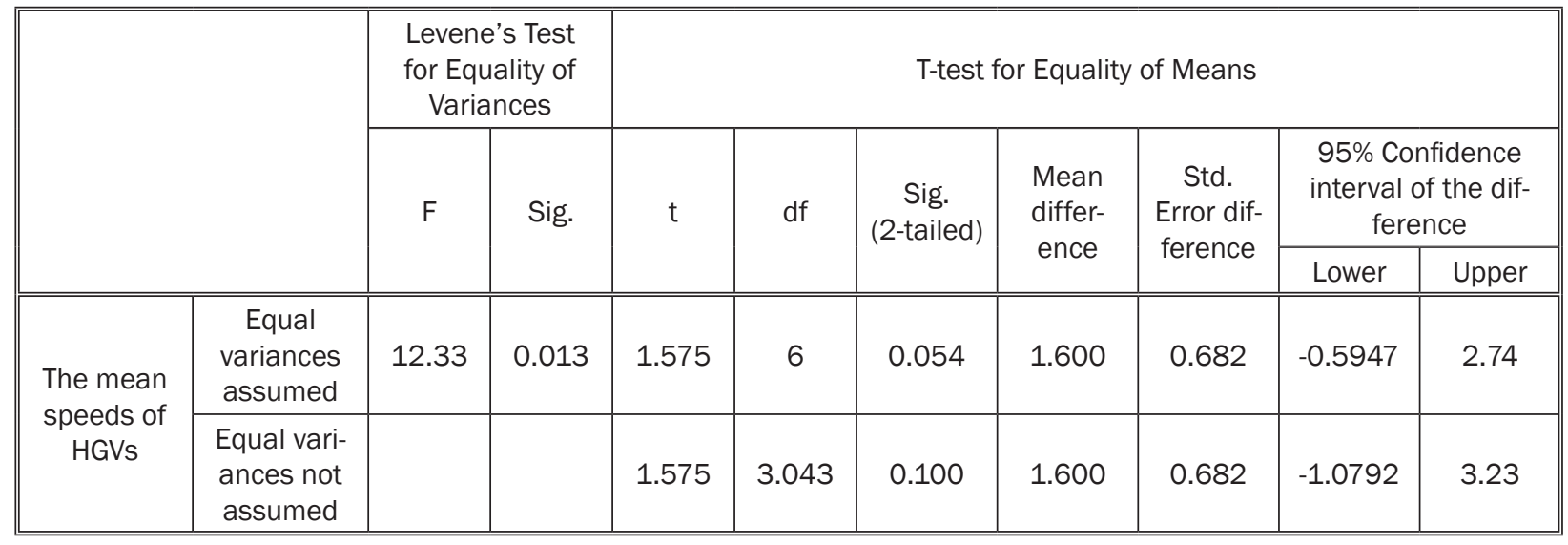

Table 11 - Recommended values of the "Five-Point Method"

\begin{tabular}{|c|c|c|c|c|c||}
\hline $\begin{array}{c}\text { Cumulative frequency of desired } \\
\text { speed distribution }\end{array}$ & $0 \%$ & $15 \%$ & $50 \%$ & $85 \%$ & $100 \%$ \\
\hline \hline Desired speed of Cars $(\mathrm{km} / \mathrm{h})$ & 85 & 91 & 106 & 121 & 127 \\
\hline Desired speed of HGVs $(\mathrm{km} / \mathrm{h})$ & 66 & 70 & 75 & 81 & 85 \\
\hline
\end{tabular}




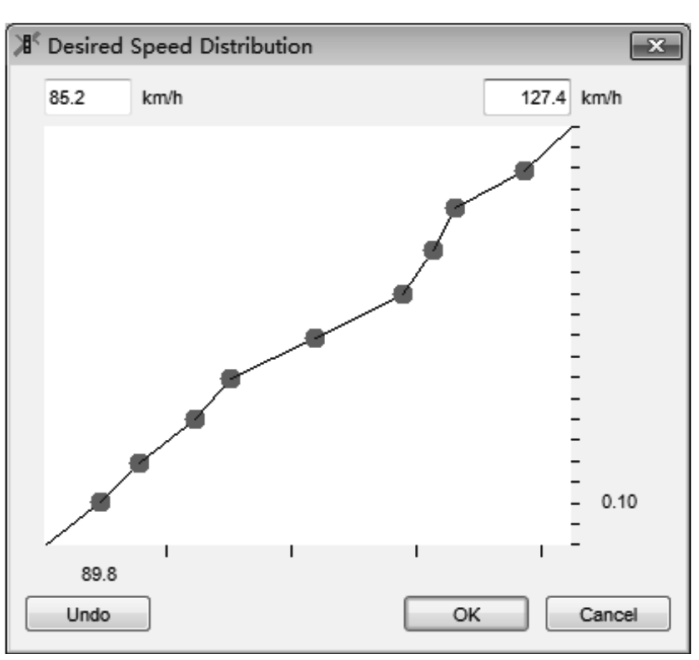

(a) Ten-Point method (Cars)

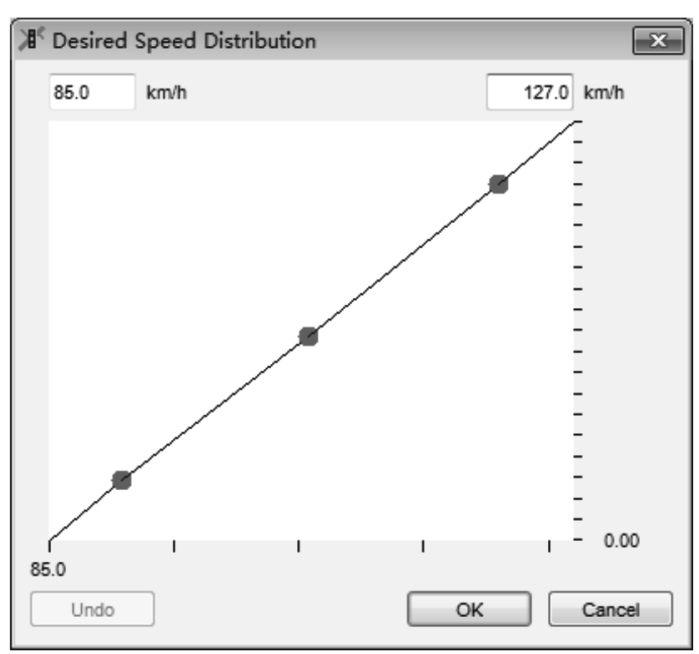

(a) Five-Point method (Cars)

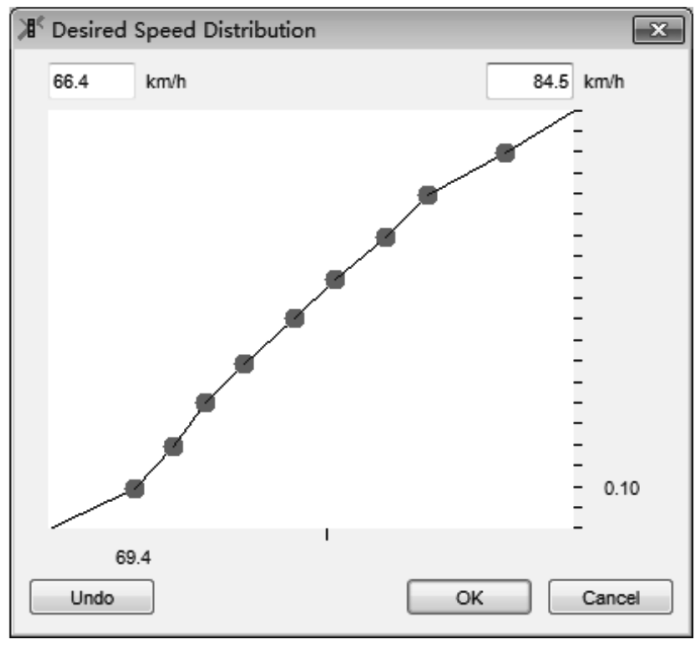

(b) Ten-Point method (HGVs)

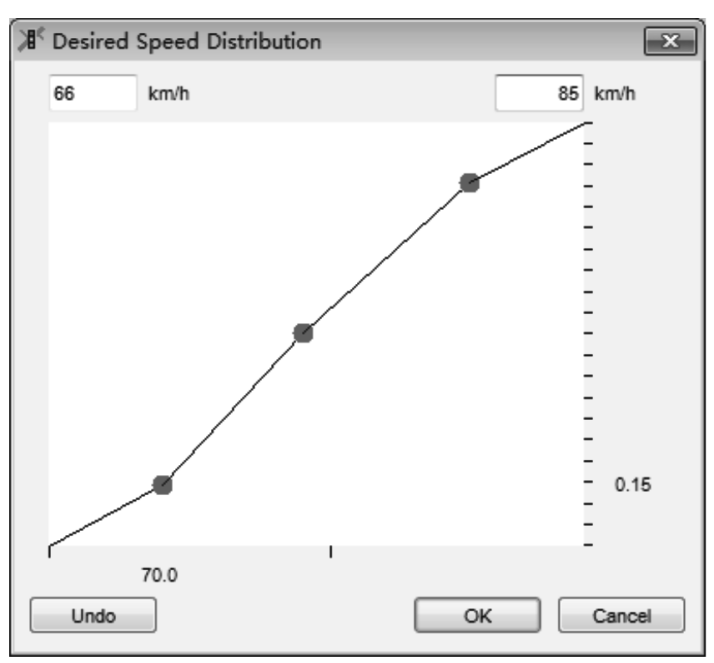

(b) Five-Point method (HGVs)

Figure 4 - Comparison of the desired speed distributions calibrated by two methods

consistently around $60 \mathrm{~km} / \mathrm{h}$. Comparing the speeds in reality and in the simulation with the default speed distribution, the importance of calibrating the desired speed distribution was very evident.

After analysing the results of two calibration methods, both were relatively close to the reality. The TenPoint Method was validated previously. In reference to the Five-Point Method, T-tests showed that p-values were 0.111 for Cars and 3.324 for HGVs. Thus, we had reason to believe that the simulated speeds were very close to the real speeds. The mean relative error for Cars in the "Default without speed limit" was 5.19\% and $22.19 \%$ for HGVs - significantly higher than either the Ten-Point or Five-Point relative error measures. The mean relative error of the Ten-Point Method was $3.59 \%$ for Cars, and $2.24 \%$ for HGVs. This can be compared to relative error from the Five-Point Method which was $3.64 \%$ for Cars and $1.43 \%$ for HGVs. Thus, the desired speed distributions calibrated using the Five-Point Method were also effective, and the convenience was greater than using the Ten-Point Method. Therefore, the Five-Point Method was suitable for calibrating the traffic simulation model in highway temporary work zones. 


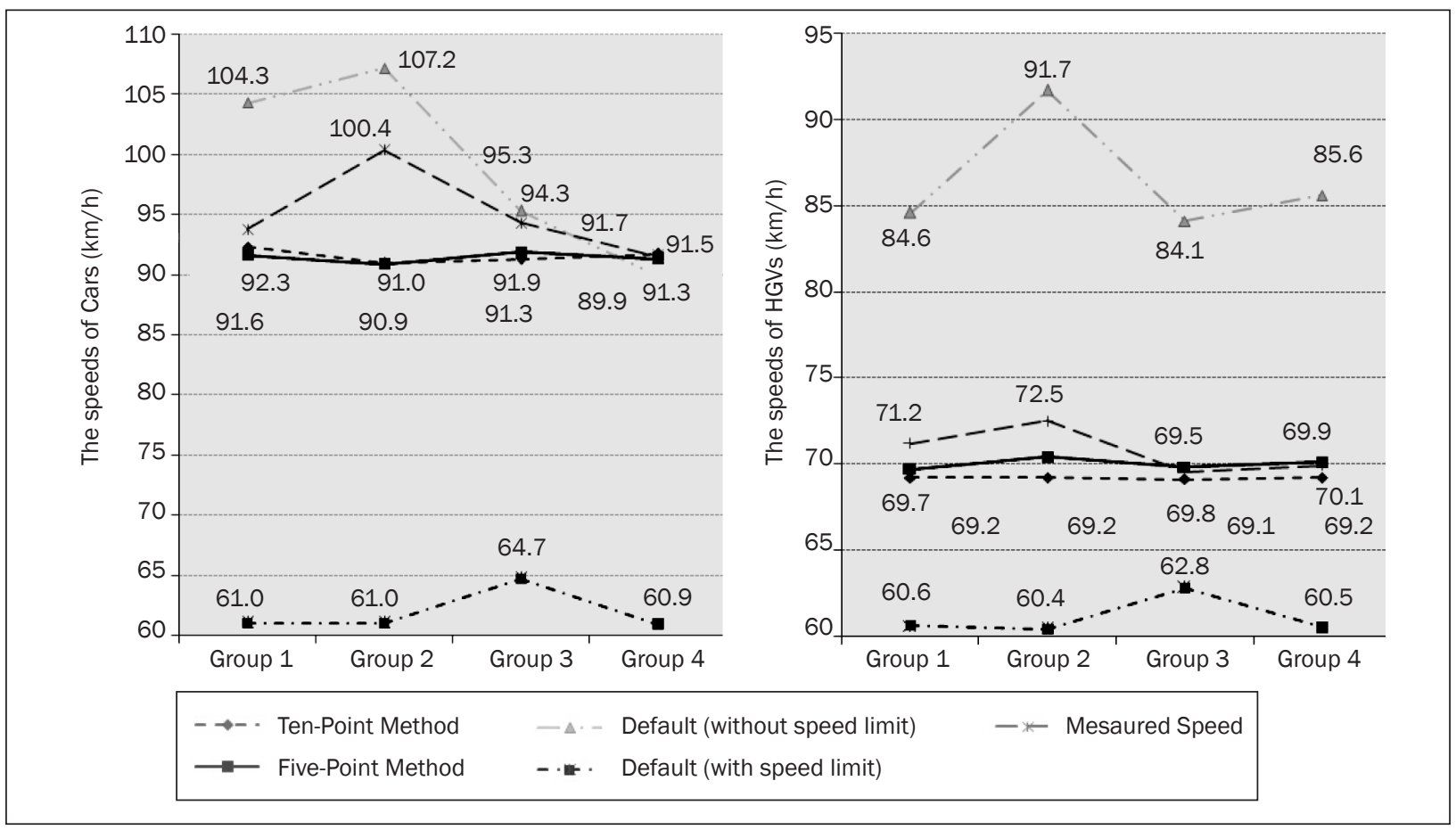

Figure 5 - Comparison among the measured and different simulated speeds

\section{CONCLUSIONS AND FUTURE WORK}

Parameter calibration is essential for microscopic traffic simulation models. However, the existing studies of parameter calibration are limited to driver behaviour parameters and car-following parameters, and do not address the calibration methods to focus on the desired speed distribution for temporary work zones. The vehicle speed played a vital role in the studies, especially in work zones with respect to road safety, and the desired speed is an important parameter in Vissim that has a significant influence on the achievable travel speeds, roadway capacity, travel time, etc. Thus, it would be valuable for micro-simulation if the desired speed distribution could be calibrated simply and usefully. This study is motivated by the need to complement the traditional calibration of micro-simulation models. This paper is the first to propose a new calibration method for the desired speed distribution for temporary work zones, called the "Five-Point Method". The calibration method was proposed in five steps: (1) data collection and analysis, (2) plotting of the travelling speed cumulative frequency curves and calibration of the desired speed distribution, (3) simulation runs and validation of the simulation results, and (4) proposal of a new calibration method. The simulations of four sets of field data were performed; the results show that the calibration method is promising, when adopting factor $k$ between the desired speed and the travelling speed. The proposed $\mathrm{k}$ for Cars and HGVs are 1.200 and 1.098, respectively. The results of simulations which adopted the Ten-Point Method to calibrate the desired speed distribution shows that the average relative errors between the measured speed and the simulation speed are $2.76 \%$ for Cars, and $1.56 \%$ for HGVs. Considering that the previous method of calibration is complicated and time-consuming, a simplified calibration method, the "Five-Point Method", is provided with the recommended values for each control point. Compared to $5.19 \%$ of Cars and $22.19 \%$ of HGVs in the simulation adopted the default desired speed distribution without calibration, the average relative error came down to $3.64 \%$ of Cars, and $1.43 \%$ of HGVs by using the Five-Point Method to calibrate the desired speed distribution. Therefore, the desired speed distributions calibrated using the FivePoint Method were kept as simple as possible, while still retaining the realistic distributions at 95\% confidence level.

To arrive at a more realistic representation of the drivers' behaviour, calibrating a single parameter may not provide a global optimal solution. More research is needed for combining the calibrated desired speed distribution with the calibration of the driver behaviour parameters. Recommendations for future research include revising the "Five-Point Method" under different traffic conditions such as congested highways.

\section{ACKNOWLEDGMENTS}

The authors would like to acknowledge the support provided by Special Fund for Basic Scientific Research of Central Colleges, Chang'an University (No. CHD2011JC048 and CHD2013G2211005) and Doctoral Fund of Ministry of Education of China (20120205120013) and Basic Research Fund of 
Ministry of Transportation (2014319812170). Their support has been gratefully acknowledged.

张驰, 副教授, 博士学位

邮箱: zhangchi@chd.edu.cn

长安大学, 公路学院,

教育部特殊地区公路工程重点实验室，陕西省，中 国

刘时雨，硕士学位

邮箱: paozimaza@foxmail.com

长安大学, 公路学院,

教育部特殊地区公路工程重点实验室，陕西省，中 国

JENNIFER OGLE, Associate Professor, Ph.D.

Email: ogle@clemson.edu

Clemson University,

Glenn Department of Civil Engineering, South Carolina, USA

张敏, 讲师, 博士学位

邮箱:zhangmin@chd.edu.cn

长安大学, 公路学院,

交通工程研究所，陕西省，中国

一种用于临时养护区微观仿真模型中期望速度的标 定新方法

\section{摘要}

目前针对长期养护区参数标定的研究仅局限于驾驶 员行为参数和跟车行为参数, 而对于临时养护区中 期望速度分布的标定研究还存在着空白。通过临时 养护区的仿真实验难以获得真实有效的数据, 而如 果能够有一种应用于高速公路临时养护区交通仿真 模型中期望速度分布的标定方法, 则能够获得更加 真实的仿真数据。该标定方法分为五个步骤：（1） 采集与分析数据; (2) 绘制行驶速度累计频率曲线 图并标定期望速度分布；（3）进行仿真实验；（4 ) 验证仿真结果; (5) 提出一种新的标定方法。该 方法经过T检验后发现其结果十分理想。最后, 提出 了一种名为简化后的标定方法, 称为 “五点法”, 并给出了五点法中取值的建议值。

关键词

交通仿真; 参数标定; 期望速度分布; 临时养护 区; Vissim

\section{REFERENCES}

[1] Schonfeld P, Chien S. Optimal work zone lengths for two-lane highways. Journal of Transportation Engineering. 1999;125(1):21-29.

[2] Asad JK, Aemal JK, Forrest MC. Effects of Work Zone Presence on Injury and Non-injury Crashes. Accident Analysis \& Prevention. 2002;(34):19-29.

[3] Rouphail NM, Yang ZS, Fazio J. Comparative study of short-and long-term urban freeway work zones; 1988.

[4] Pigman JG, Agent KR. Highway Accidents in Construction and Maintenance Work Zone. Transportation Research Record: Journal of the Transportation Research Board. 1990;1270:12-21.
[5] Summary Report on Work Zone Accidents. Standing Committee on Highway Traffic Safety. American Association of State Highway and Transportation Officials; July 1987.

[6] Park BB, Schneeberger JD. Microscopic simulation model calibration and validation: case study of VISSIM simulation model for a coordinated actuated signal system. Transportation Research Record: Journal of the Transportation Research Board. 2003;1856:185192.

[7] Yu L, Chen XM, Wan T, Guo JF. Calibration of VISSIM for Bus Rapid Transit Systems in Beijing 23 Using GPS Data. Journal of Public Transportation. 2006;9(3):239257.

[8] Hollander Y, Liu R. The principles of calibrating traffic micro simulation models. Transportation. 2008;35(3):347-362.

[9] Benekohal RF. Procedure for validation of microscopic traffic flow simulation models; 1991.

[10] Hellinga BR. Requirements for the calibration of traffic simulation models. Proceedings of the Canadian Society for Civil Engineering. 1998;4:211-222.

[11] Lee DH, Yang X, Chandrasekar P. Parameter Calibration for PARAMICS Using Genetic Algorithm. Transportation Research Board 80th Annual Meeting, 2001 Jan 7-11; Washington, DC.

[12] Richard D, Joseph H, Allen H. Guidelines for Applying Traffic Simulation Modeling Software. Oakland, CA: Dowling Associates Inc; 2002.

[13] Hourdakis J, Michalopoulos PG, Kottommannil J. A practical procedure for Calibrating Microscopic Traffic Simulation Models. Transportation Research Board 82nd Annual Meeting, 2002 Jan; Washington, DC.

[14] Gomes G, May A, Horowitz R. A Micro-simulation Model of a Congested Freeway using VISSIM. 83rd Annual Meeting of the Transportation Research Board, 2004 Jan 11-15; Washington, DC.

[15] Jian S, Yang XG. Research into Microscopic Traffic Simulation Model Systematic Parameter Calibration: A Case Study of VISSIM. Computer and Communications. 2004;3.

[16] Jie S. Evaluations of Traffic Simulation Models: CORSIM and SimTruck. Nova Scotia, Canada: Dalhousie University; 2005.

[17] Yang H, Han SF, Chen XH. The application of parameters calibration in Vissim. Journal of Urban Transportation. 2006;4(5):22-25.

[18] Li ZM, Yan XY. A calibration method for micro-simulation based on Genetic Algorithm. Journal of Transport Standardization. 2006;4:21-23.

[19] Ciuffo BF, Punzo V, Torrieri V. A framework for the calibration of microscopic traffic flow models, Transportation Research Board 86th Annual Meeting, 2007 Jan 21-25; Washington, DC.

[20] Jian S, Yang XG, Liu HD. The calibration study of Micro-simulation model. Journal of System Simulation. 2007;19(1):48-50,159.

[21] Chitturi MV, Benekohal RF. Calibration of VISSIM for Freeways. Transportation Research Board 87th Annual Meeting, 2008 Jan 13-17; Washington, DC.

[22] Lee JB, Ozbay K. Calibration of a Macroscopic Traffic Simulation Model Using Enhanced Simultaneous Perturbation Stochastic Approximation Methodology. 
Transportation Research Board 87th Annual Meeting, 2008 Jan 13-17; Washington, DC.

[23] Li YX. The analysis and modeling of capacity of expressway with bus lane based on Micro-simulation. Beijing Jiaotong University; 2009.

[24] Yang W. Study on the relationship between the access of urban expressway and bus station based on Micro-simulation. Beijing University of Technology; 2010.

[25] Ting $\mathrm{H}$. Calibration of microscopic traffic simulation model for weaving sections expressway. Beijing Jiaotong University; 2010.

[26] Yu Z, Lei Y, Zhao NL, Zhu LY, Chen XM. The study of SPSA used to calibrate parameters in Vissim. Journal of Transportation Systems Engineering. 2010;10(4):4449.

[27] Zhang CC, Niu XQ. Parameter calibration of VISSIM model for intersection based on orthogonal experiment. Transportation Science \& Technology. 2011;(2):110-113.

[28] Quan Y, Meng W, Deng XH. Simulation parameter calibration of single signal intersection based on orthogonal experiment. Journal of Highway and Transportation Research and Development. 2012:57-63.

[29] Liu CC. The study of road safety in work zone based on simulation. Southwest JiaoTong University, Chengdu, China; 2012.

[30] Hu XH, Yu Z. Parameters calibration method for large scale traffic simulation network based on SPGA algo- rithm. Journal of Educational Institute of Jilin Province. Richards SH, Dudek CL, Implementation of work zone speed control measures. Transportation Research Record: Journal of the Transportation Research Board. 1986;1086:36-42.

[31] Virginia PS, Richard WL. Study of Speed Patterns in Work Zones. The 78th Annual Meeting of the Transportation Research Board, Washington, DC, revised. 1999:978-992.

[32] Migletz J, Graham JL, Anderson IB, et al. Work Zone Speed Limit Procedure. The 78th Annual Meeting of the Transportation Research Board, Washington, DC. 1999:584-596.

[33] Park BB, Qi H. Development and evaluation of a calibration and validation procedure for microscopic simulation models. Charlottesville, Virginia: Virginia Transportation Research Council; 2004.

[34] Zhao XF, Huang ZY, Lin HF. The effects of traffic delay on desired speed distribution. Journal of Transportation and Computers. 2007;24(6):84-87.

[35] Peng WX, Yuan X, Guan JX, Dong HL. The profiles of travelling speed based on simulation in Vissim. Journal of Hebei Jiaotong College. 2007;4(4):57-60.

[36] Peng WX, Yuan X, Guan JX, Dong HL. The profiles of travelling speed based on simulation in Vissim. Journal of Hebei Jiaotong College. 2007;4(4):57-60. 